\title{
REDUCTION OF WOOD CONSUMPTION FOR GLULAM ARCH BY ITS STRENGTHENING
}

\author{
Aiva Kukule ${ }^{1}$, Karlis Rocens ${ }^{2}$ \\ ${ }^{1,2}$ Department of Structural Engineering and Reconstruction, Faculty of Civil Engineering, Riga Technical University, \\ Azenes Str. 16, LV-1048 Riga, Latvia \\ E-mail: ${ }^{1}$ aiva.kukule@rtu.lv; ${ }^{2}$ rocensk@latnet.lv
}

\begin{abstract}
This paper focuses on possibilities to reduce wood consumption for 11 glulam arches with rise-span ratio selected from $1 / 7$ to $1 / 2$. The most loaded sections of each arch are strengthened in 7 different ways: by attaching non-prestressed glass fiber-reinforced-polymer (GFRP) and carbon-fiber-reinforced polymer (CFRP) laminates, by attaching prestressed GFRP and CFRP laminates, with steel reinforcement bars and by attaching prestressed GFRP and CFRP laminates to the reinforced arch. Efficiency rates of various strengthening types are compared and also the use of design resistance is estimated. The span of arches is assumed constant $-42 \mathrm{~m}$. The arches are subjected to snow load $s_{0}=1.5 \mathrm{kN} / \mathrm{m}^{2}$ and wind load $w_{0}=0.23 \mathrm{kN} / \mathrm{m}^{2}$. It is verified that compressive, bending, shear and tensile stress in wood fibres does not exceed design strength value as well as stress in FRP laminate and steel reinforcement bars does not exceed their design resistances and the anchorage of reinforcement is provided. Analytical calculations confirmed that maximum cross-section reduction can be achieved by attaching prestressed CFRP laminates to reinforced arch resulting in wood consumption reduction up to $31 \%$.
\end{abstract}

Keywords: GFRP, CFRP, reinforcing, prestressing, creep.

\section{Introduction}

Cross section dimensioning of uniform section glulam arch is done based on stresses in the most loaded section. Therefore, less loaded sections are designed with high strength reserve. To save materials variable section height along arch length is preferable. Unfortunately, production of such structural element is complicated. It is possible to avoid the imperfections listed above by using a uniform section arch with reduced cross-section dimensions and strengthened most loaded sections.

The influence of FRP laminate and steel reinforcement bars on cross-section of wood construction has been previously studied (Brunner, Schnueriger 2005; Dagher et al. 2010). In this report two methods of reducing wood arch cross-section dimensions are analysed. The first method involves reducing the wood cross-section dimensions by substituting part of it with materials with higher strength and higher elastic modulus. Glulam arch is subjected to combined bending and compression. Therefore the second method involves prestressing the glulam arch. Prestressing induces tensile stresses which compensate compressive stresses caused by operating loads.

For prestressing the structures fibre-reinforced polymer (FRP) laminates are increasingly used. The most common are carbon-fiber-reinforced polymer (CFRP) laminates. Carbon fibres are much more expensive than glass fibres, but also have much higher mechanical properties (Alann 2006).

The objective of this research is to analyse possibilities for cross-section reduction using structures strengthening methods listed above.

\section{Characteristics of the research object}

Rise-span ratio $f / L$ of three hinged curved arches selected $1 / 7$ to $1 / 2$, span $-42 \mathrm{~m}$, step $-6 \mathrm{~m}$. Arches are strengthened in 7 different ways: by attaching non-prestressed GFRP and CFRP laminates, by attaching prestressed GFRP and CFRP laminates, with steel reinforcement bars and by attaching prestressed GFRP and CFRP laminates to the reinforced arch. The reinforcement is variable along the length of the arch. Each section is minimally reinforced to ensure its load-bearing capacity (Fig. 1).

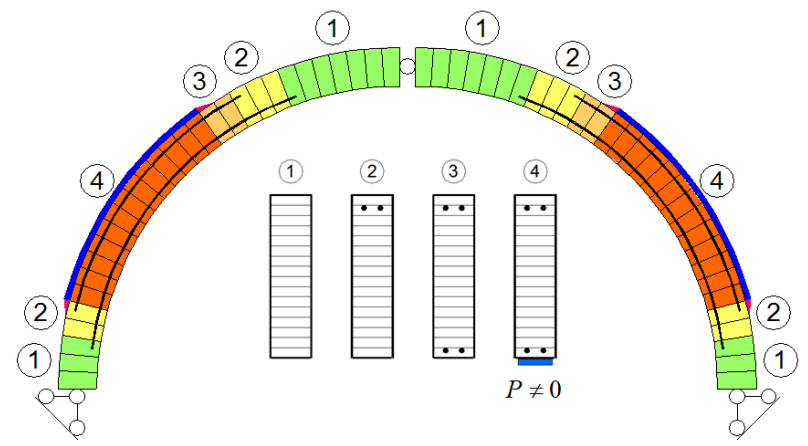

Fig. 1. Reinforced arch prestressed with FRP laminate: 1 - non-reinforced section; 2 - reinforcement bars placed only in more compressed zone of cross-section; 3 - reinforcement bars placed along the top and bottom faces of the arch; 4 - reinforcement bars placed along the top and bottom faces of the arch, section prestressed with GFRP or CFRP laminate; $\mathrm{P}$ - prestressing force of the laminate.

Arches made of $33 \mathrm{~mm}$ thick second class pine wood boards with design compressive strength along the grain and design bending strength $R_{c, 0, d}=R_{m, d}=15 \mathrm{MPa}$, design tensile strength perpendicular to the grain $R_{t, 90, d}=0,3 \mathrm{MPa}$ and design shear strength $R_{v, d}=1,5 \mathrm{MPa}$. Design compressive and bending strengths are multiplied by a factor $\gamma_{c}$ that takes into account effect of cross-sectional depth $h$ (Table 1). Wood elastic modulus parallel to the grain $-E_{w}=10 \mathrm{MPa}$ (LBN 206-99). 
Table 1. Coefficient $\gamma_{\mathrm{c}}$.

\begin{tabular}{|c|c|c|c|c|c|c|}
\hline $\mathrm{h}, \mathrm{cm}$ & $\leq 50$ & 60 & 70 & 80 & 100 & $\geq 120$ \\
\hline$\gamma_{\mathrm{c}}$ & 1.0 & 0.96 & 0.93 & 0.90 & 0.85 & 0.8 \\
\hline
\end{tabular}

The most loaded section of arch with rise-span ratio $1 / 2.0$ is reinforced by using 4 class $A I I$ steel bars with a diameter of $25 \mathrm{~mm}$, while the others are reinforced by using bars with a diameter of $22 \mathrm{~mm}$. This is the maximum amount of reinforcement in accordance with the structural reinforcement placement requirements if the reinforcement bars are placed in a single layer along the upper and lower edges of the cross-section (Fig. 7, section 1-1). Design tensile strength of steel reinforcement bars $-R_{s}=280 \mathrm{MPa}$, elastic modulus $E_{s}=210 \mathrm{GPa}$. (LBN 203-97)

Cross-sectional dimensions of „Tyfo” GFRP laminate are $101.6 \times 1.9 \mathrm{~mm}$, characteristic tensile strength $R_{G F R P}=896.3 \mathrm{MPa}$, elastic modulus of tension parallel to the grain $-E_{G F R P}=41.4 \mathrm{GPa}$. Cross-sectional dimensions of ,Tyfo" CFRP laminate are $150 \times 1.4 \mathrm{~mm}$, characteristic tensile strength $-R_{C F R P}=2900 \mathrm{MPa}$, elastic modulus of tension parallel to the grain $-E_{C F R P}=190 \mathrm{GPa}$. Design tensile strength of FRP laminate:

$$
\begin{aligned}
& R_{G F R P, d}=\frac{R_{G F R P} \eta_{G F R P}}{\gamma_{G F R P}}=\frac{896.3 \cdot 0.75}{1.3}=517.1 \mathrm{MPa}, \\
& R_{C F R P, d}=\frac{R_{C F R P} \eta_{C F R P}}{\gamma_{C F R P}}=\frac{2900 \cdot 0.95}{1.2}=2295.8 \mathrm{MPa},
\end{aligned}
$$

where $R_{G F R P, d}, R_{C F R P, d}$ - design tensile strength of GFRP and CFRP laminate, MPa; $\eta_{G F R P}, \eta_{C F R P}-$ operating conditions factor if structure is protected against weather, not exposed to aggressive substances and cyclic loading; $\gamma_{G F R P}, \gamma_{C F R P}$ - partial factor for material properties if during FRP laminate attaching environmental conditions and bonding process are controlled (GangaRao, Hota 2007).

\section{Design loads}

During operation the arch is loaded with self-weight, snow and wind loads. Design value of roof panel selfweight $-g_{p}=0.718 \mathrm{kN} / \mathrm{m}^{2}$. Characteristic value of snow load $-s_{0}=1.5 \mathrm{kN} / \mathrm{m}^{2}$, of wind load $-w_{0}=0.23 \mathrm{kN} / \mathrm{m}^{2}$. Terrain category - B. Design values of loads are given in Table 2. Arch load diagram and combinations are shown in Figure 2. (SNiP 2.01.07-85*)

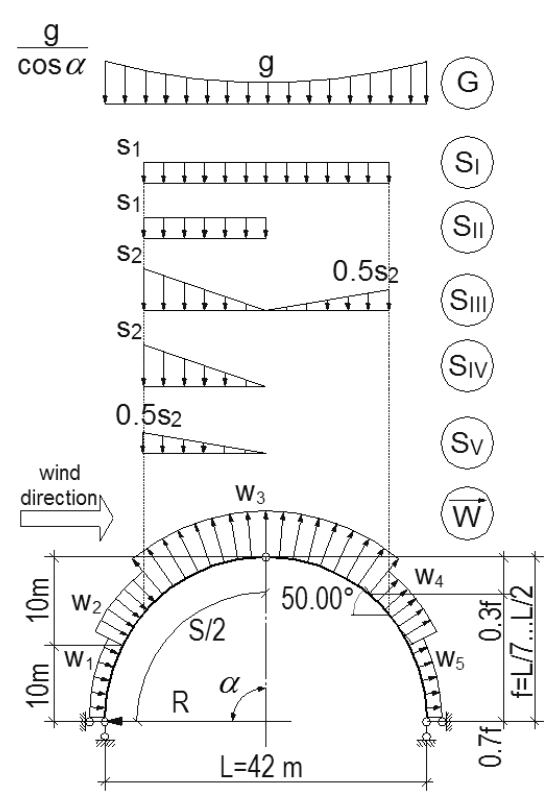

1) $G$

2) $G+S_{I}$

3) $G+S_{I I}$

4) $G+S_{I I I}$

5) $G+S_{I V}$

6) $G+S_{V}$

7) $G+\vec{W}$

8) $G+0,9 \cdot\left(S_{I}+\vec{W}\right)$

9) $G+0,9 \cdot\left(S_{I I}+\vec{W}\right)$

10) $G+0,9 \cdot\left(S_{I I I}+\vec{W}\right)$

11) $G+0,9 \cdot\left(S_{I V}+\vec{W}\right)$

12) $G+0,9 \cdot\left(S_{V}+\vec{W}\right)$

13) $G+0,9 \cdot\left(S_{I I}+\overleftarrow{W}\right)$

14) $G+0,9 \cdot\left(S_{I I I}+\overleftarrow{W}\right)$

15) $G+0,9 \cdot\left(S_{I V}+\overleftarrow{W}\right)$

16) $G+0,9 \cdot\left(S_{V}+\overleftarrow{W}\right)$

Fig. 2. Load diagram and combinations: $\mathrm{G}$ - roof construction self-weight load; $\mathrm{S}_{\mathrm{I}}, \mathrm{S}_{\mathrm{II}}, \mathrm{S}_{\mathrm{III}}, \mathrm{S}_{\mathrm{IV}}, \mathrm{S}_{\mathrm{V}}$ - snow load; W - wind load; $\alpha$ - semicircle central angle; $f$ - rise of arch; $L$ - span of arch; $\mathrm{R}$ - arch curvature radius; $\mathrm{S}$ - arch length.

\section{Arch prestressing technology}

During operation depending on the load diagram arch top and bottom faces can be subjected to compression or tension (Fig. 3). FRP laminate is attached to the more tensioned face.

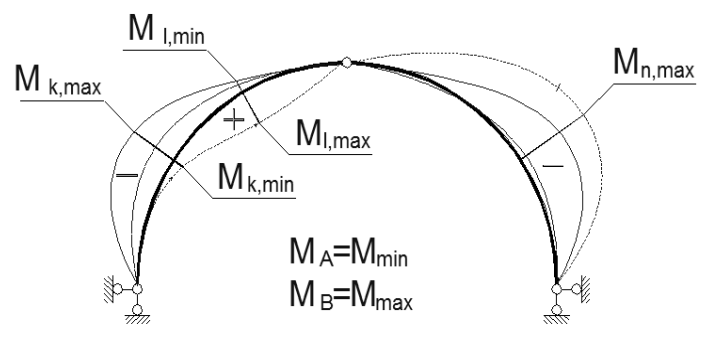

Fig. 3. Bending moment distribution along the length of the arch: $M_{B}-$ maximum bending moment (scheme „B”); $M_{A}$ - maximum bendng moment opposing moment $\mathrm{M}_{\mathrm{B}}$ if diffrent load combinations are used (scheme „A”).

\begin{tabular}{|c|c|c|c|c|c|c|c|c|c|c|c|}
\hline \multirow{2}{*}{ Load } & \multicolumn{11}{|c|}{ Rise-span ratio f/L } \\
\hline & $1 / 7.0$ & $1 / 6.5$ & $1 / 6.0$ & $1 / 5.5$ & $1 / 5.0$ & $1 / 4.5$ & $1 / 4.0$ & $1 / 3.5$ & $1 / 3.0$ & $1 / 2.5$ & $1 / 2.0$ \\
\hline $\mathrm{g}$ & 5.57 & 5.48 & 5.51 & 5.57 & 5.64 & 5.64 & 5.64 & 5.64 & 5.64 & 5.79 & 6.13 \\
\hline S1 & 12.60 & 11.70 & 10.80 & 9.90 & 9.00 & 8.10 & 7.20 & 6.30 & 5.76 & 5.76 & 5.76 \\
\hline $\mathrm{s}_{2}$ & 18.73 & 20.49 & 22.56 & 25.25 & 28.52 & 30.7 & 31.68 & 31.68 & 31.68 & 31.68 & 31.68 \\
\hline $\mathrm{w}_{1}$ & 0.15 & 0.16 & 0.18 & 0.20 & 0.23 & 0.30 & 0.38 & 0.47 & 0.59 & 0.75 & 0.88 \\
\hline $\mathrm{W}_{2}$ & 0.15 & 0.16 & 0.18 & 0.20 & 0.23 & 0.30 & 0.38 & 0.47 & 0.59 & 0.91 & 1.15 \\
\hline $\mathrm{w}_{3}$ & -0.86 & -0.90 & -0.94 & -0.99 & -1.05 & -1.12 & -1.21 & -1.31 & -1.46 & -1.72 & -2.00 \\
\hline $\mathrm{W}_{4}$ & -0.41 & -0.42 & -0.43 & -0.45 & -0.47 & -0.49 & -0.50 & -0.50 & -0.50 & -0.61 & -0.66 \\
\hline W5 & -0.41 & -0.42 & -0.43 & -0.45 & -0.47 & -0.49 & -0.50 & -0.50 & -0.50 & -0.50 & -0.50 \\
\hline
\end{tabular}

Table 2. Design values of loads, kN/m. 
To ensure fine adhesion between the wood section and FRP laminate surface planning and cleaning is carried out before arch prestressing. If the FRP laminate is attached to the bottom face of the arch, at first FRP laminate is partly prestressed by using a prestressing device. Another part of necessary prestressing force is gained by using a press device. To prestress the upper face of the arch only the prestressing device is used (Fig. 4).
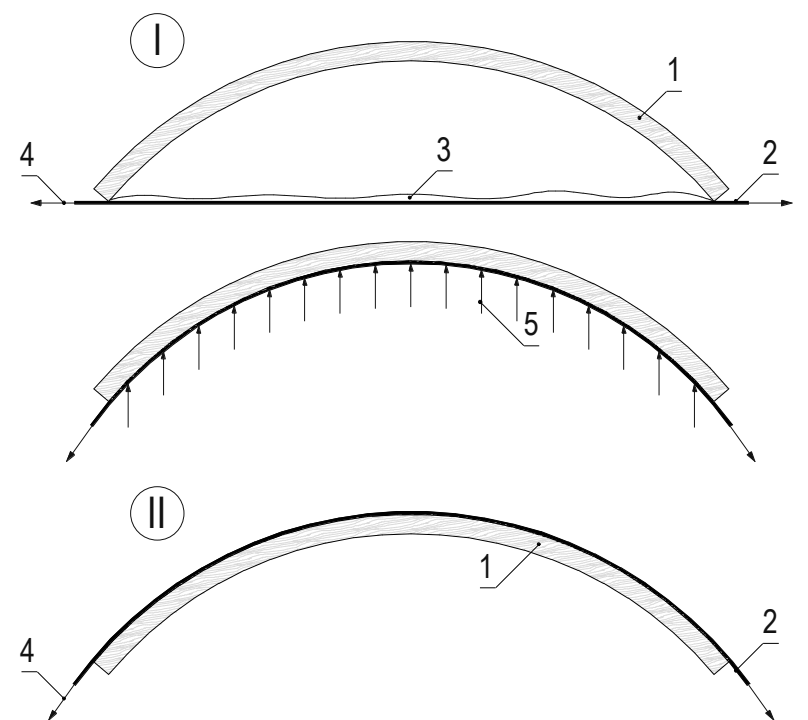

Fig. 4. Prestressing glulam arch by attaching FRP laminate to the bottom $(I)$ and upper $(I I)$ faces of the arch: 1 - glulam arch; 2 - FRP laminate; 3 - epoxy-based adhesive; 4 - tensioning direction of the prestressing device; 5 - pressing direction.

Short anchoring area of high prestressing force induces concentrated force redistribution from FRP laminate ends to the strengthened element. High stresses perpendicular to the wood grain are arising resulting in delamination of FRP laminate ends. To avoid it gradual anchoring technique is used (Brunner, Schnueriger 2005).

\section{Prestressing force of FRP laminate}

Loads applied to arch cause deformation of wood fibers that changes the value of prestressing force $P$ (Fig. 5).

Immediately after prestressing force $P$ and bending moment $M=P \cdot h_{l}$ induce deformation of wood fibers. Prestressing force of FRP laminate after development of stress losses during prestressing stage:

$$
N_{p, 0}=N_{p}-\Delta N_{p, 0}=\frac{N_{p}}{1+\frac{E_{F R P} A_{F R P}}{E_{w}}\left(\frac{1}{A_{\text {red }}}+\frac{h_{1}^{2}}{I_{\text {red }}}\right)},
$$

where $N_{p}$ - initial prestressing force of FRP laminate, $\mathrm{kN} ; N_{p, 0}-$ prestressing force of FRP laminate after development of stress losses during prestressing stage, $\mathrm{kN} ; \Delta N_{p, 0}-$ stress losses during prestressing stage, $\mathrm{kN} ; h_{l}$ - distance between gravity center of section and FRP laminate, $\mathrm{m} ; A_{F R P}$ - cross-sectional area of FRP laminate, $\mathrm{m}^{2} ; A_{\text {red }}$ - cross-sectional area of composite cross-section equated to glulam cross-section, $\mathrm{m}^{2}$; $I_{\text {red }}$ - second moment of area of composite cross-section equated to glulam cross-section, $\mathrm{m}^{4} ; E_{F R P}$ - elastic modulus of FRP laminate, $\mathrm{kPa} ; E_{w}$ - elastic modulus of wood, kPa. (Schnüriger et al. 2007)

(I)

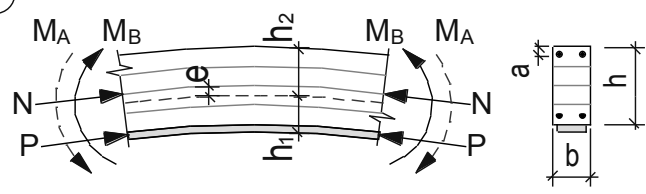

(II)

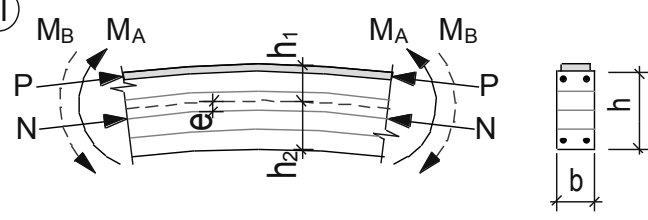

Fig. 5. Forces in prestressed section: $I-$ FRP laminate attached to the bottom face of the arch; II - FRP laminate attached to the upper face of the arch; $M_{B}$ - maximum bending moment (acting contrary to the prestressing force $P$ effect); $M_{A}$ - maximum bending moment opposing moment $M_{B}$, if different load combinations are used (amplifies prestressing force $P$ effect); $N$ - axial force; $b$ - width of cross-section; $h$ - depth of crosssection; $h_{1}, h_{2}$ - distance between gravity center of section and outer fibre; $a$ - distance between gravity center of reinforcement bar and outer fibre; $e$ - distance between gravity centers of non-reinforced glulam cross-section and composite cross-section equated to glulam cross-section, $\mathrm{m}$.

After mounting the arch is subjected to roof structure self-weight load that changes the value of prestressing force:

$$
N_{p, 1}^{(\varphi=0)}=\frac{N_{p, 0}-\frac{E_{F R P} A_{F R P}}{E_{w}}\left(\frac{N_{g}}{A_{\text {red }}}-\frac{\left(N_{g} e+M_{g}\right) h_{1}}{\xi_{\text {red }, g} I_{\text {red }}}\right)}{1+\frac{E_{F R P} A_{F R P}}{E_{w}}\left(\frac{1}{A_{\text {red }}}\right)+\frac{h_{1}^{2}}{\xi_{\text {red,g }} I_{\text {red }}}},
$$

where $N_{g}$ - roof structure self-weight load induced axial force, $\mathrm{kN} ; M_{g}$ - roof construction self-weight load induced bending moment if FRP laminate is attached to bottom face of arch, $\mathrm{kNm} ; M_{g}=-M_{g}$ - roof construction self-weight load induced bending moment if FRP laminate is attached to the upper face of the arch, $\mathrm{kNm}$; $e$ - distance between gravity centers of non-reinforced glulam cross-section and composite cross-section equated to glulam cross-section, m; $\xi_{\text {red,g }}$ - coefficient that takes into account additional bending moment induced by axial force and deflection if arch is subjected to roof construction self-weight load.

Creep deformation of wood in fiber direction arises with the time under the roof construction self-weight loading. This effect is taken into account by using coefficient $\varphi(t)=0.6$ that corresponds to normal conditions (Schnüriger et al. 2007). 
Prestressing force of FRP laminate after creep deformation of wood arises if the arch is loaded by roof construction self-weight:

$$
N_{p, 1}^{(\varphi=0.6)}=\frac{N_{p, 1}^{(\varphi=0)}-\frac{\varphi(t) E_{F R P} A_{F R P}}{E_{w}}\left(\frac{N_{g}}{A_{\text {red }}}-\frac{\left(N_{g} e+M_{g}\right) h_{1}}{\xi_{\text {red }, g} I_{\text {red }}}\right)}{1+\frac{\varphi(t) E_{F R P} A_{F R P}}{E_{w}}\left(\frac{1}{A_{\text {red }}}+\frac{h_{1}^{2}}{\xi_{\text {red,g }} I_{\text {red }}}\right)} .
$$

Snow and wind loads induce immediate deformations that change prestressing force of FRP laminate:

$$
N_{p, 2}^{(\varphi=0)}=\frac{N_{p, 1}-\frac{E_{F R P} A_{F R P}}{E_{w}}\left(\frac{N}{A_{\text {red }}}-\frac{(N e+M) h_{1}}{\xi_{\text {red }} I_{\text {red }}}\right)}{1+\frac{E_{F R P} A_{F R P}}{E_{w}}\left(\frac{1}{A_{\text {red }}}+\frac{h_{1}^{2}}{\xi_{\text {red }} I_{\text {red }}}\right)},
$$

where $N_{p, 1}=N_{p, 1}{ }^{(\varphi=0)}$ - prestressing force of FRP laminate before creep deformation of wood has arisen if the arch is loaded by roof construction self-weight, $\mathrm{kN}$; $N_{p, l}=N_{p, l}{ }^{(\varphi=0.6)}-$ prestressing force of FRP laminate after creep deformation of wood has arisen if the arch is loaded by roof construction self-weight, $\mathrm{kN} ; N$ - axial force induced by all operating loads, $\mathrm{kN} ; M=-M_{A}-$ bending moment induced by all operating loads if section is loaded according to scheme ,A”, $\mathrm{kNm} ; M=M_{B}$ - bending moment induced by all operating loads if section is loaded according to scheme „B”, $\mathrm{kNm}$; $\xi_{\text {red }}$ - coefficient that takes into account additional bending moment induced by axial force and deflection if the arch is subjected to all operating loads.

In case FRP laminate is extra tensioned due to operating loads $\left(M=M_{B}\right)$, prestressing force is calculated by taking in account creep deformations of wood:

$$
N_{p, 2}^{(\varphi=0.6)}=\frac{N_{p, 2}^{(\varphi=0)}-\frac{\varphi(t) \psi_{2} E_{F R P} A_{F R P}}{E_{w}}\left(\frac{N_{B}}{A_{\text {red }}}-\frac{\left(N_{B} e+M_{B}\right) h_{1}}{\xi_{\text {red }} I_{\text {red }}}\right)}{1+\frac{\varphi(t) \psi_{2} E_{F R P} A_{F R P}}{E_{w}}\left(\frac{1}{A_{\text {red }}}+\frac{h_{1}^{2}}{\xi_{\text {red }} I_{\text {red }}}\right)}
$$

where $\Psi_{2}=0,2$ - coefficient that converts variable actions to equivalent permanent actions in order to derive the creep loading on the structure (Porteous, Kermani 2007); $N_{B}$ - axial force induced by all operating loads if the section is loaded according to scheme „B”, $\mathrm{kN}$.

Entire FRP laminate is prestressed with constant force $P=N_{p}$, except anchorage of it ends. Laminate is minimally prestressed to ensure that wood compressive stresses and FRP laminate tensile stresses do not exceed their strength during prestressing and operation stage.

\section{Cross-sectional dimensioning methodology}

First minimum cross-sectional height of the non-reinforced arch is determined according to the allowed slenderness:

$$
h=n t \geq \frac{0,58 S \sqrt{12}}{\lambda},
$$

where $h$ - depth of cross-section, m; $n$ - number of boards; $t=0,033 \mathrm{~m}$ - board thickness; $S$ - arch length, m; $\lambda=120-$ allowed slenderness ratio of the arch in the plane of bending moment. (LBN 206-99)

To ensure local stability of the arch, cross-section width of $b \geq h / 8$ is assumed (Fig. 5). The arch is divided into 60 equal sections. According to load diagram bending moment, axial and shear forces for each design cross-section are estimated (Fig. 2). Additional bending moment induced by axial force and deflection has been taken into account by the coefficient $\xi$ :

$$
\begin{aligned}
& \xi=1-\frac{N_{0}}{\varphi R_{c, 0, d} \gamma_{c} A_{w}}, \\
& \lambda=\frac{0,58 \sqrt{12} S}{h}, \\
& \lambda \leq 70 \Rightarrow \varphi=1-k_{\varphi 1}\left(\frac{\lambda}{100}\right)^{2}, \\
& \lambda>70 \Rightarrow \varphi=\frac{k_{\varphi 2}}{\lambda^{2}},
\end{aligned}
$$

where $N_{0}-$ axial force in the section of arch ridge, $\mathrm{kN}$; $\varphi$ - buckling coefficient; $R_{c, 0, d} \gamma_{\mathrm{c}}-$ design compressive strength of wood along the grain, $\mathrm{kPa} ; A_{w}-$ crosssectional area of non-reinforced section, $\mathrm{m}^{2} ; S-$ arch length, $\mathrm{m} ; \lambda$ - slenderness ratio corresponding to bending about strong axis; $\mathrm{k}_{\varphi 1}=0,8, \mathrm{k}_{\varphi 2}=3000-$ coefficients (LBN 206-99).

According to equations (14) - (22) values of stresses in the non-reinforced arch are verified (geometrical characteristics of FRP laminate and reinforcement bars as well as prestressing force assumed to be zero). Overloaded sections of the arch are reinforced and according to equations (9) - (12) coefficient $\xi_{\text {red }}$ for the reinforced arch is determined by substituting slenderness $\lambda$ with $\lambda_{\text {red }}$ :

$$
\lambda_{\text {red }}=\frac{0,58 n S}{\sum_{i=1}^{60} \sqrt{\frac{I_{\text {red }, i}}{A_{\text {red }, i}}}}
$$

where $S$ - arch length, m; $A_{\text {red }, i}$ - cross-sectional area of composite cross-section equated to glulam crosssection, $\mathrm{m}^{2} ; I_{\text {red, } i}$ - second moment of area of composite cross-section equated to glulam cross-section, $\mathrm{m}^{4}$.

From equations (3) - (7) and (18) - (22) initial prestressing force of FRP laminate is derived. Crosssectional strength is verified and cross-section depth is increased by one board till the strength conditions are satisfied.

Equations for verification of axial stresses are given in Table 3. 
Table 3. Verification for axial stresses.

\begin{tabular}{|c|c|c|c|c|c|}
\hline \multirow{2}{*}{\multicolumn{3}{|c|}{ Equation }} & \multirow{3}{*}{$\begin{array}{c}\begin{array}{c}\text { Prestressing } \\
\text { stage }\end{array} \\
h_{i}=h_{2}\end{array}$} & \multicolumn{2}{|c|}{ Operational stage } \\
\hline & & & & \multirow{2}{*}{$\begin{array}{l}\text {,A” } \\
h_{i}=h_{2}\end{array}$} & \multirow{2}{*}{,B” } \\
\hline$\sigma_{w, t}=\frac{N+P}{A_{\text {red }}}-\frac{\left(M+\left(N e-P h_{1}\right) \cdot(-1)^{k}\right) h_{i}}{\xi_{\text {red }} I_{\text {red }}} \leq R_{m, d}$ & $\gamma_{c}$ & (14) & & & \\
\hline$\sigma_{s, t}=\left(\frac{N+P}{A_{\text {red }}}-\frac{\left(M+\left(N e-P h_{1}\right) \cdot(-1)^{k}\right)\left(h_{i}-a\right)}{\xi_{\text {red }} I_{\text {red }}}\right)$ & $\frac{E_{s}}{E_{w}} \leq 0.8 R_{s}$ & (15) & \multirow{2}{*}{$\begin{array}{c}P=N_{p, 0} \\
N=M=0 \\
\xi_{r e d}=1 \\
k=1\end{array}$} & \multirow{2}{*}{$\begin{array}{c}P=N_{p, 2}^{(\varphi=0)} \\
N=N_{A} \\
M=M_{A} \\
k=1\end{array}$} & \multirow{2}{*}{$\begin{array}{c}P=N_{p, 2}^{(\varphi=0)} \\
N=N_{B} \\
M=M_{B} \\
k=2\end{array}$} \\
\hline$\sigma_{w, c}=\frac{N+P}{A_{\text {red }}}+\frac{\left(M+\left(N e-P h_{1}\right) \cdot(-1)^{k}\right) h_{i}}{\xi_{\text {red }} I_{\text {red }}} \leq R_{c, \text {, }}$ & $0, d \gamma_{c}$ & (16) & & & \\
\hline$\sigma_{s, c}=\left(\frac{N+P}{A_{\text {red }}}+\frac{\left(M+\left(N e-P h_{1}\right) \cdot(-1)^{k}\right)\left(h_{i}-a\right)}{\xi_{\text {red }} I_{\text {red }}}\right.$ & $\frac{E_{s}}{E_{w}} \leq 0,8 R_{s}$ & (17) & $h_{i}=h_{1}$ & $h_{i}=h_{1}$ & $h_{i}=h_{2}$ \\
\hline$\sigma_{F R P}=\frac{P}{A_{F R P}} \leq R_{F R P}$ & & (18) & $P=N_{p}$ & - & $P=N_{p, 2}^{(\varphi=0.6)}$ \\
\hline \multicolumn{6}{|c|}{$\begin{array}{l}\text { where } \sigma_{w, t}, \sigma_{w, c}-\text { design tensile and compressive stress along the wood grain, } \mathrm{kPa} ; \sigma_{s, t}, \sigma_{s, c}-\text { design tensile and compressive stress } \\
\text { in reinforcement bars, } \mathrm{kPa} ; \sigma_{F R P}-\text { design tensile stress in FRP laminate, } \mathrm{kPa} ; R_{m, d} \gamma_{\mathrm{c}}-\text { design bending strength, } \mathrm{kPa} ; R_{c, 0, d} \gamma_{\mathrm{c}}- \\
\text { design compressive strength along the wood grain, } \mathrm{kPa} ; R_{s}-\text { design tensile strength of steel reinforcement bars, } \mathrm{kPa} ; R_{F R P}- \\
\text { design tensile strength of FRP laminate, } \mathrm{kPa} ; N \text { - axial force induced by all operating loads, } \mathrm{kN} ; P \text { - prestressing force of FRP } \\
\text { laminate, } \mathrm{kN} ; M-\text { bending moment induced by all operating loads, } \mathrm{kNm} ; a-\text { distance between gravity center of reinforcement } \\
\text { bar and outer fibre, m; } e-\text { distance between gravity centers of non-reinforced glulam cross-section and composite cross-section } \\
\text { equated to glulam cross-section, } \mathrm{m} ; h_{i} \text { - distance between gravity center of section and outer fibre; } A_{F R P}-\text { cross-sectional area of } \\
\text { FRP laminate, } \mathrm{m}^{2} ; A_{r e d}-\text { cross-sectional area of composite cross-section equated to glulam cross-section, } \mathrm{m}^{2} ; I_{r e d}-\text { second } \\
\text { moment of area of composite cross-section equated to glulam cross-section, } \mathrm{m}^{4} ; E_{s} \text { - elastic modulus of steel reinforcement bars, } \\
\mathrm{kPa} ; E_{w}-\text { elastic modulus of wood, } \mathrm{kPa} ; \xi_{r e d}-\text { coefficient that takes into account additional bending moment induced by axial } \\
\text { force and deflection. }\end{array}$} \\
\hline
\end{tabular}

If the bending moment tends to increase the radius of curvature, tensile stresses values of wood perpendicular to the grain are verified:

$$
\frac{\left(M+\left(N e-P h_{1}\right) \cdot(-1)^{k}\right) h_{i}^{2}}{2 \xi_{\text {red }} I_{\text {red }}\left(R+\left(0,5 h-h_{2}\right) \cdot(-1)^{k}\right)} \leq R_{t, 90, d},
$$

where $M$ - bending moment induced by all operating loads, $\mathrm{kNm}$; $N$ - axial force induced by all operating loads, $\mathrm{kN} ; P$ - prestressing force of FRP laminate, $\mathrm{kN}$; $e$ - distance between gravity centers of non-reinforced glulam cross-section and composite cross-section equated to glulam cross-section, $\mathrm{m} ; h$-depth of cross-section, m; $h_{i}$ - distance between gravity center of section and outer fibre, $\mathrm{m} ; R$ - arch curvature radius, $\mathrm{m} ; I_{\text {red }}-$ second moment of area of composite cross-section equated to glulam cross-section, $\mathrm{m}^{4} ; \xi_{\text {red }}$ - coefficient that takes into account additional bending moment induced by axial force and deflection; $R_{t, 90, d}$ - design tensile strength of wood perpendicular to the grain, $\mathrm{kPa} ; M=M_{A}(k N m)$, $h_{i}=h_{2}(m), k=1$ if FRP laminate attached to upper face of $\operatorname{arch} ; \quad M=M_{B}(k N m), h_{i}=h_{1}(m), k=2$ if FRP laminate attached to bottom face of arch (Fig. 5).
Various forces in adjacent sections induce different wood fiber deformations and prestressing force change. As a result, the tangential stresses are caused not only by operational loads, but also by the prestressing force (Fig. 6):

$$
\begin{aligned}
& \tau=\frac{Q_{i} S_{i}^{*}}{\xi_{\text {red }} I_{\text {red }, i} b} \leq R_{v, d}, \text { (Grin' et al. 1990) } \\
& Q_{i}=Q_{e, i}+\frac{P_{i} h_{1, i}-P_{i-1} h_{1, i-1}}{\Delta s}
\end{aligned}
$$

where $\tau$ - shear stress, $\mathrm{kPa} ; Q_{i}$ - total shear force in design section, $\mathrm{kN} ; Q_{e, i}$ - shear force induced by operating loads, $\mathrm{kN} ; b$ - width of cross-section, $\mathrm{m}$; $S_{i}^{*}$ - first moment of area about central axis, $\mathrm{m}^{3}$; $\xi_{\text {red }}$ - coefficient that takes into account additional bending moment induced by axial force and deflection; $I_{\text {red,i }}$ - second moment of area of composite cross-section equated to glulam cross-section, $\mathrm{m}^{4} ; R_{v, d}$ - design shear strength of wood, $\mathrm{kPa} ; P_{i}, P_{i-1}-$ prestressing force in the adjacent design sections, $\mathrm{kN} ; h_{l, i}, h_{1, i-1}$ - distance between gravity center of section and FRP laminate, m; $\Delta s$-distance between design sections, $\mathrm{m}$. 

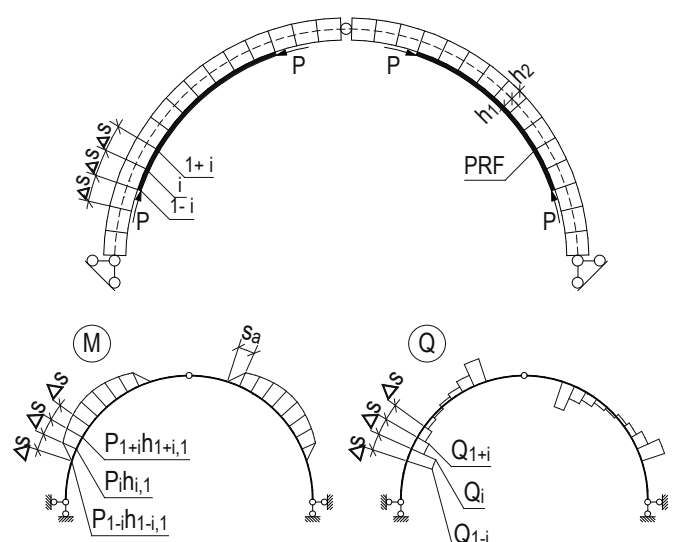

Fig. 6. Variable prestressing induced shear force: $\mathrm{M}$ - bending moment diagram; $\mathrm{Q}$ - shear force diagram; $\mathrm{P}$ - prestressing force; $h_{1}, h_{2}-$ distance between gravity center of section and outer fibre; $\Delta \mathrm{s}=\mathrm{S} / 60$ - distance between design sections, where $\mathrm{S}$ - length of the arch; $\mathrm{s}_{\mathrm{a}}$ - anchorage length of FRP laminate; $\mathrm{i}-$ designed cross-section.

Verifying whether reinforcement on the ends zones can lose anchorage with wood (Fig. 7):

$$
\sigma_{s} A_{s} \leq 0,1 R_{v, d} \pi l_{g}(d+0,5)\left(1,2-0,02 l_{g} / d\right) \text {, }
$$

where $\sigma_{s}-$ stress in reinforcement bars, $\mathrm{kPa}$; $A_{s}$ - cross-sectional area of rebar, $\mathrm{m}^{2} ; R_{v, d}$ - design shear strength of wood, $\mathrm{kPa} ; d$ - diameter of rebar, $\mathrm{cm}$; $10 d \leq l_{g} \leq 30 d$ - rebar anchorage length, m. (LBN 206-99)

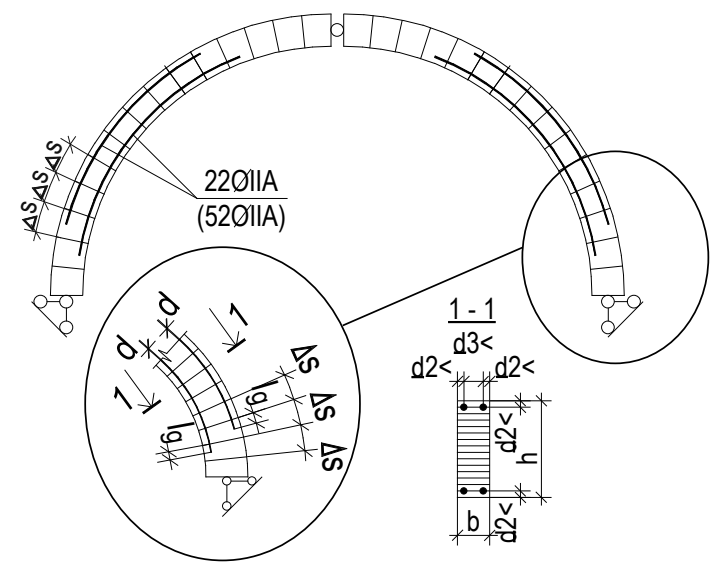

Fig. 7. Anchorage of reinforcement bars: $d$ - diameter of rebar; $\mathrm{b}$ - arch cross section width; $\mathrm{h}$ - arch cross section height; $l_{\mathrm{g}}$ - rebar anchorage length; $\Delta \mathrm{s}-$ distance between designed sections.

Arch stability is not verified because it is assumed to be provided by using the roof panels and bracing.

\section{Results}

Rise-span ratio affects the maximum absolute value and action direction of bending moment. Bending moment of each analysed arch reaches its maximum positive and maximum negative value in different sections. In maximum bending moment section "i" reversal bending moment can occur if different loading diagram is applied. The exception is arch with rise-span ratio of $1 / 2.0$, which is subjected only to negative bending moment in this section. For arches with rise-span ratio $1 / 7.0,1 / 3.0,1 / 2.5$ and $1 / 2.0$ maximum bending moment is negative, but for the remaining arches it is positive (Fig. 8).

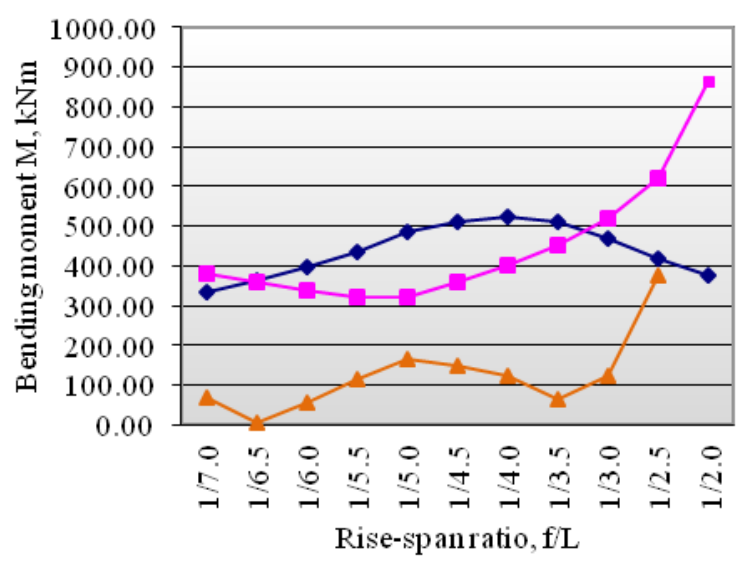

$$
\multimap(+) \mathrm{M} \longrightarrow(-) \mathrm{M} \longrightarrow \Delta \mathrm{Mi}
$$

Fig. 8. Bending moment $M$ values during operation stage: $(+) M-$ maximum value of positive bending moment; $(-) M$ - the maximum absolute value of negative bending moment; $\Delta M_{i}$ - maximum difference between absolute values of reversal bending moments in the most loaded section , $i$ ".

Some types of reinforcement are not analyzed in detail because the same wood consumption can be obtained by using a less expensive solution. Results are classified according to the most loaded section and shown in Table 4, Fig. 9, Fig. 10 and Fig. 11. It can be seen that prestressing is possible to be realized in arches with higher difference between maximum values of reverse bending moments in section ,i”. The exception are arches whose cross-sectional dimensions are determined with the strength reserve due to the assumed thickness of the board.

Use of non-prestressed GFRP laminate increases wood cross-section area and second moment respectively for 0.4 and $1.1 \%$ that is insufficient to reduce arch section.

Efficiency of arch strehgthening by prestressed GFRP and non-prestressed CFRP has random nature because cross-section can be reduced by not more than one layer of board.

Prestressed GFRP laminate replaced with prestressed CFRP laminate may further reduce the cross-section of arch because CFRP laminate properties have higher effect on glulam equated cross-section geometrical characteristics in addition allowing higher prestressing force.

Cross-section of some reinforced arches can not be additionally reduced by using prestressed FRP laminate because the allowed prestressing force of the reduced cross-section is insufficient to compensate bending moment induced by operating loads. 
Table 4. Reinforcement effect on the arch cross-sectional dimensions.

\begin{tabular}{|c|c|c|c|c|c|c|c|c|c|c|}
\hline \multirow{2}{*}{$\mathrm{f} / \mathrm{L}$} & \multirow{2}{*}{$\begin{array}{c}\mathrm{R}_{\mathrm{w}}, \\
\%\end{array}$} & $\begin{array}{c}\Delta \mathrm{M}_{\mathrm{i}}, \\
\mathrm{kNm}\end{array}$ & \multicolumn{9}{|c|}{ Type of reinforcement } \\
\hline & & $\mathrm{W}$ & $\mathrm{G}$ & $\mathrm{C}$ & $\mathrm{GN}$ & $\mathrm{CN}$ & $\mathrm{S}$ & GNS & $\mathrm{CNS}$ \\
\hline $1 / 7.0$ & 2.1 & 55.0 & $170 \times 1353$ & $(1)$ & $(1)$ & $(1)$ & $165 \times 1287^{*}$ & $160 \times 1254^{*}$ & $155 \times 1221^{*}$ & $(3)$ \\
\hline $1 / 6.5$ & 9.5 & 6.9 & $165 \times 1320$ & $(1)$ & $165 \times 1287^{*}$ & $(1)$ & $(2)$ & $155 \times 1221^{*}$ & $(4)$ & $(4)$ \\
\hline $1 / 6.0$ & 3.5 & 58.8 & $165 \times 1320$ & $(1)$ & $165 \times 1287^{*}$ & $165 \times 1287^{*}$ & $(3)$ & $155 \times 1221^{*}$ & $(4)$ & $(4)$ \\
\hline $1 / 5.5$ & 4.5 & 117.6 & $170 \times 1353$ & $(1)$ & $165 \times 1320^{*}$ & $165 \times 1320^{*}$ & $165 \times 1287^{*}$ & $155 \times 1221^{*}$ & $(4)$ & $(4)$ \\
\hline $1 / 5.0$ & 4.5 & 164.4 & $175 \times 1386$ & $(1)$ & $170 \times 1353^{*}$ & $170 \times 1353^{* *}$ & $165 \times 1287^{*}$ & $160 \times 1254^{*}$ & $155 \times 1221^{* *}$ & $(3)$ \\
\hline $1 / 4.5$ & 1.4 & 151.1 & $175 \times 1386$ & $(1)$ & $(1)$ & $170 \times 1353^{* *}$ & $165 \times 1320^{*}$ & $165 \times 1287^{*}$ & $160 \times 1254^{* *}$ & $155 \times 1221^{*}$ \\
\hline $1 / 4.0$ & 0.1 & 123.7 & $175 \times 1386$ & $(1)$ & $(1)$ & $170 \times 1353^{* *}$ & $(3)$ & $165 \times 1287^{*}$ & $160 \times 1254^{* *}$ & $155 \times 1221^{*}$ \\
\hline $1 / 3.5$ & 3.9 & 66.6 & $175 \times 1386$ & $(1)$ & $170 \times 1353^{*}$ & $170 \times 1353^{*}$ & $(3)$ & $160 \times 1254^{*}$ & $(4)$ & $155 \times 1221^{*}$ \\
\hline $1 / 3.0$ & 3.0 & 123.6 & $175 \times 1386$ & $(1)$ & $170 \times 1353^{*}$ & $(1)$ & $(2)$ & $160 \times 1254^{*}$ & $(4)$ & $155 \times 1221^{*}$ \\
\hline $1 / 2.5$ & 3.5 & 375.1 & $185 \times 1452$ & $(1)$ & $180 \times 1419^{*}$ & $180 \times 1419^{* *}$ & $175 \times 1386^{*}$ & $170 \times 1353^{*}$ & $165 \times 1287^{* *}$ & $160 \times 1254^{* *}$ \\
\hline $1 / 2.0$ & 2.5 & - & $205 \times 1617$ & $(1)$ & $200 \times 1584^{*}$ & $200 \times 1584^{* *}$ & $190 \times 1485^{*}$ & $190 \times 1485^{*}$ & $185 \times 1452^{* *}$ & $170 \times 1353^{* *}$ \\
\hline
\end{tabular}

Legend: $f / L$ - rise-span ratio; $R_{w}$ - load-bearing capacity reserve in the most loaded section of the non-reinforced arch; $\Delta M_{i}-$ maximum difference between absolute values of reversal bending moments in the most loaded section ,, $i$ ”; $G$ - non-prestressed GFRP laminate; $C$ - non-prestressed CFRP laminate; $G N$ - prestressed GFRP laminate; $C N$-prestressed CFRP laminate; $S$ - steel reinforcement bars; GNS - with GFRP laminate prestressed reinforced arch; CNS - with CFRP laminate prestressed reinforced arch; $b \times h-$ cross-section dimensions, $\mathrm{mm}$. Reinforcement is not applicable because: $(1)$ - it is impossible to reduce cross-section; (2) prestressed FRP laminate can be replaced with non-prestressed laminate; (3) - CFRP laminate can be replaced with GFRP laminate; (4) - the arch can be strengthened by using steel rebars only. Allowed prestressing force limited by: ${ }^{*}$ - design compressive strength along the wood grain; ${ }^{* *}$ - design tensile strength of FRP laminate.

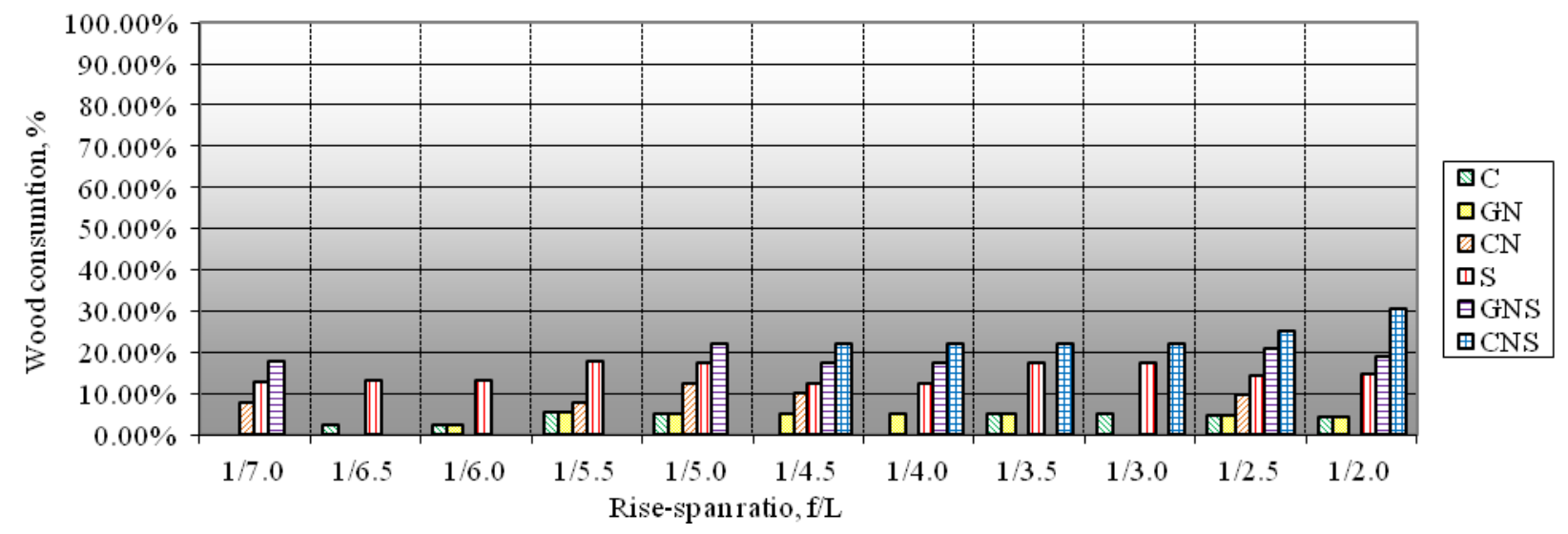

Fig. 9. Wood consumption for glulam arch.

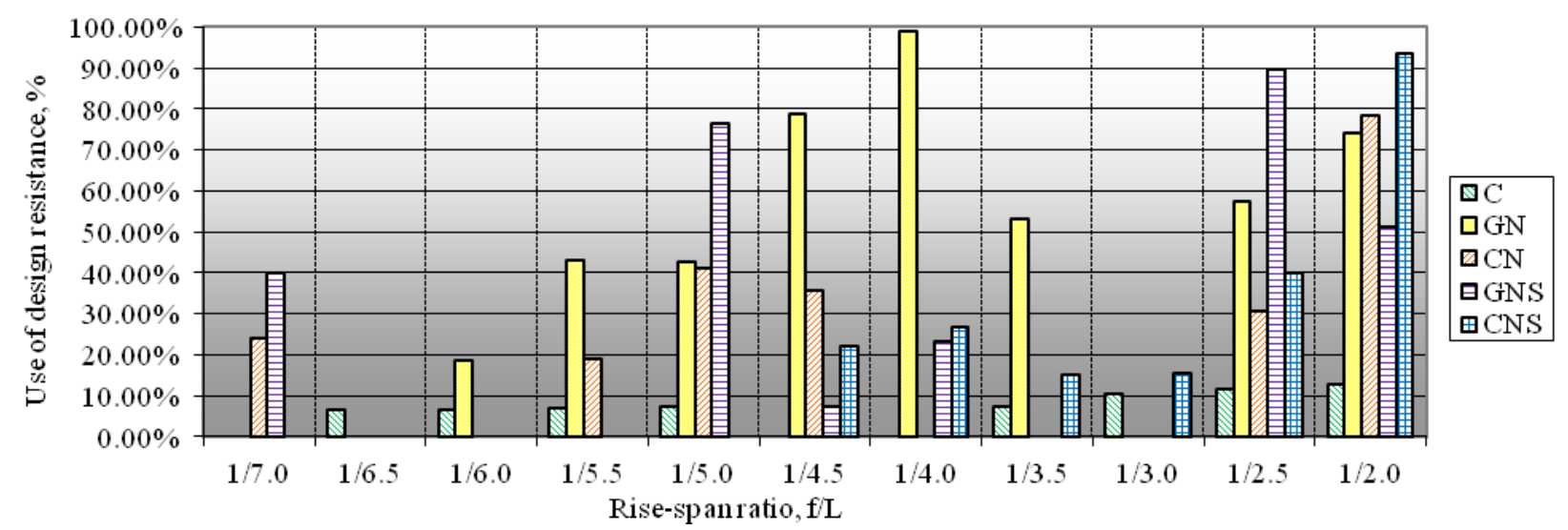

Fig. 10. Use of FRP laminate resistance. 


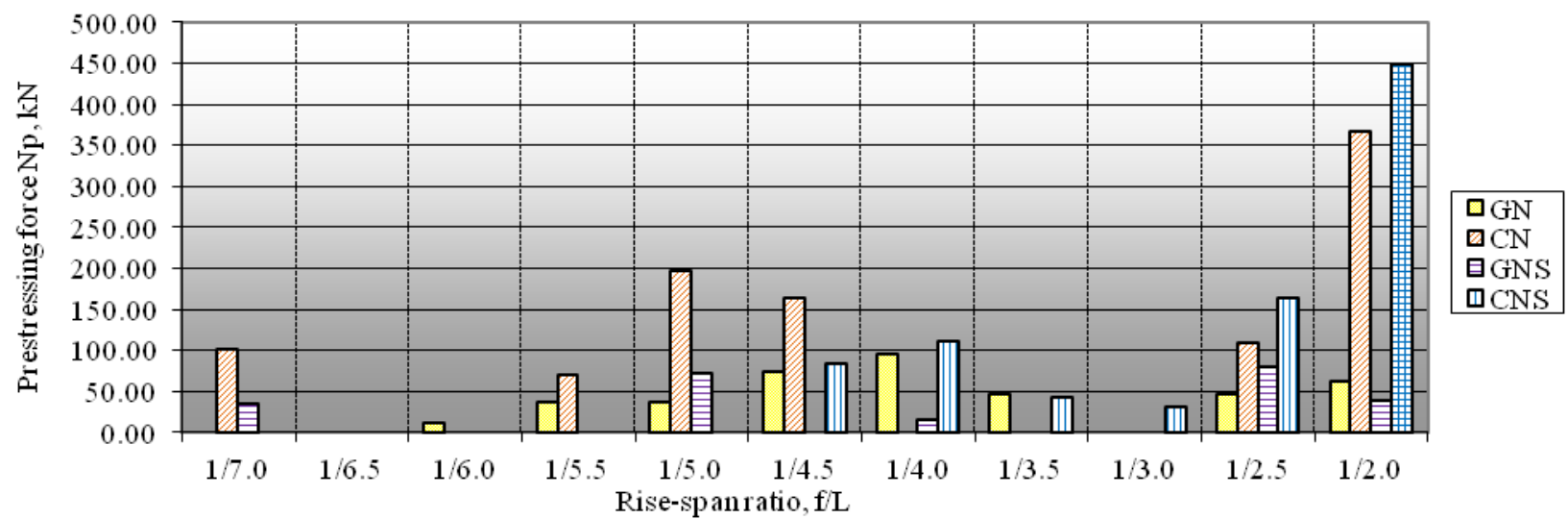

Fig. 11. FRP laminate prestressing force.

\section{Conclusions}

The conclusions are valid only if the quantity of steel reinforcement does not exceed $0.7 \%$ from the total crosssectional area, arches are loaded using loading diagrams defined in the paper and ultimate limit state is determinative in the design of arch cross-sections.

Strengthening of the arch with non-prestressed GFRP laminate is not useful because laminate cross-section size and elastic modulus effect on arch cross-sectional geometric characteristics is insufficient to cause reduction of wood cross-sectional area. Also strengthening with non-prestressed CFRP is not rational, not more than $13 \%$ of laminates design strength is used and the reduction of wood cross-sectional area does not exceed 5\%.

Non-reinforced arch prestressing with GFRP laminate is not rational because it is possible to reduce wood crosssectional area not more than by $5 \%$. That does not justify the difficulties of prestressing technology. Whereas by prestressing the reinforced arch stresses in the laminate exceed $50 \%$ from design strength for arches with risespan ratio $1 / 5,1 / 2.5$ and $1 / 2.0$. At the same time wood cross-section is reduced by up to $19 \%-22 \%$.

Non-reinforced arch prestressing with CFRP laminates leads to the reduced consumption for glulam up to $15 \%$, at the same time, from the analysed arches only for arch with rise-span ratio $1 / 2.0$ stresses in the laminate exceed $50 \%$ of the design strength. Whereas by prestressing the reinforced arch it is possible to reduce consumption for glulam by up to $31 \%$, at the same time, for the analysed arches, except the arch with rise-span relation 1/2.0, stresses in the laminate do not exceed $50 \%$ of the design strength.
In terms of simplicity of arch strengthening the easiest way to reduce the wood cross-section is by using steel reinforcement only. This type of arch strengthening leads to reduced consumption for glulam by up to $12 \%-17 \%$.

\section{References}

Alann, A., 2006. Fibres for strengthening of timber structures. Lulea University of Technology. $121 \mathrm{p}$.

Brunner, M.; Schnueriger, M., 2005. Timber beams strengthened by attaching prestressed carbon FRP laminates with a gradiented anchoring device. International institute for FRP in construction. $8 \mathrm{p}$.

Dagher, H.; $\quad$ Gray, H.; $\quad$ Davids, W.; $\quad$ Silva-Henriquez, R.; Nader, J., 2010. Variable prestressing of FRP-reinforced glulam beams: methodology and behavior. World conference on timber engineering. $6 \mathrm{p}$.

GangaRao; Hota, V. S., 2007. Reinforced concrete design with FRP composites. Boca Raton: CRC Press. 382 p.

Grin, I. M.; Dzhan-Temirov, K. E.; Grin' V. I., 1990. Stroitel'nye konstrukcii iz dereva $i$ sinteticheskih materialov. Proektirovanie $\mathrm{i}$ raschet. Kiev: Vyshha shkola. 224 p.

$L B N$ 203-97. Betona un dzelzsbetona konstrukciju projektēšanas normas.

LBN 206-99. Koka konstrukciju projektēšanas normas.

Porteous, J.; Kermani, A., 2007. Structural Timber Design to Eourocode 5. United Kingdom: Blackwell Publishing. 555 p. http://dx.doi.org/10.1002/9780470697818

Schnüriger, M.; Brunner, M.; Lehmann, M., 2007. Verstärkung von Holzbalken mit vor-gespannten CFK-Lamellen, die in Gradienten verankert sind. Berner Fachhochschule. 43 p.

SNiP 2.01.07-85. * "Nagruzki i vozdejstvija”. 